\title{
BMJ Open Understanding the role of embarrassment in gynaecological screening: a qualitative study from the ASPIRE cervical cancer screening project in Uganda
}

\author{
Flora F Teng, ${ }^{1}$ Sheona M Mitchell, ${ }^{1}$ Musa Sekikubo, ${ }^{2}$ Christine Biryabarema, ${ }^{2}$ \\ Josaphat K Byamugisha, ${ }^{2}$ Malcolm Steinberg, ${ }^{3,4}$ Deborah M Money, ${ }^{1,5}$ \\ Gina S Ogilvie ${ }^{1,3}$
}

To cite: Teng FF,

Mitchell SM, Sekikubo M, et al. Understanding the role of embarrassment in gynaecological screening: a qualitative study from the ASPIRE cervical cancer screening project in Uganda. BMJ Open 2014;4:e004783. doi:10.1136/bmjopen-2014004783

- Prepublication history for this paper is available online. To view these files please visit the journal online (http://dx.doi.org/10.1136/ bmjopen-2014-004783).

Received 1 January 2014 Revised 12 March 2014 Accepted 18 March 2014

CrossMark

For numbered affiliations see end of article.

Correspondence to Dr Gina S Ogilvie; gina.ogilvie@bccdc.ca

\section{ABSTRACT}

Objective: To define embarrassment and develop an understanding of the role of embarrassment in relation to cervical cancer screening and self-collected human papillomavirus (HPV) DNA testing in Uganda.

Design: Cross-sectional, qualitative study using semistructured one-to-one interviews and focus groups.

Participants: 6 key-informant health workers and 16 local women, purposively sampled. Key informant inclusion criteria: Ugandan members of the project team. Focus group inclusion criteria: woman age 30-69 years, Luganda or Swahili speaking, living or working in the target Ugandan community. Exclusion criteria: unwillingness to sign informed consent.

Setting: Primary and tertiary low-resource setting in Kampala, Uganda.

Results: In Luganda, embarrassment relating to cervical cancer is described in two forms. 'Community embarrassment' describes discomfort based on how a person may be perceived by others. 'Personal embarrassment' relates to shyness or discomfort with her own genitalia. Community embarrassment was described in themes relating to place of study recruitment, amount of privacy in dwellings, personal relationship with health workers, handling of the vaginal swab and misunderstanding of HPV selfcollection as HIV testing. Themes of personal embarrassment related to lack of knowledge, age and novelty of the self-collection swab. Overall, embarrassment was a barrier to screening at the outset and diminished over time through education and knowledge. Fatalism regarding cervical cancer diagnosis, worry about results and stigma associated with a cervical cancer diagnosis were other psychosocial barriers described. Overcoming psychosocial barriers to screening can include peer-topeer education, drama and media campaigns.

Conclusions: Embarrassment and other psychosocial barriers may play a large role at the onset of a screening programme, but over time as education and knowledge increase, and the social norms around

\section{Strengths and limitations of this study}

This study is unique in the qualitative evaluation of the specific role of embarrassment in cervical cancer screening in Uganda.

- The study also provides a novel comparison between a group of women who have had previous education on cervical cancer screening compared with those who have not.

- The research team was limited in its ability to explore the perspective of all ethnic groups in the target community.

- The focus group format may have been prohibitive for the most embarrassed women to participate.

screening evolve, its role diminishes. The role of peerto-peer education and community authorities on healthcare cannot be overlooked and can have a major impact in overcoming psychosocial and social barriers to screening.

\section{INTRODUCTION}

Approximately 233700 women die in the developing world every year from cervical cancer, which is largely preventable through screening and treatable in the early stages. ${ }^{1}$ In Uganda, $80 \%$ of cervical cancer is diagnosed at stage III or IV ${ }^{2}$ largely due to a lack of screening infrastructure. With human papillomavirus (HPV) emerging as a more sensitive screening test for cervical cancer, there are opportunities for low and middle income countries (LMIC) to employ this technology to prevent cervical cancer morbidity and mortality. ${ }^{3}$ Screening programmes in the developed world have made strides in 
increasing screening uptake ${ }^{4}$ and recent advances such as high-risk human papillomavirus (hrHPV) DNA testing have improved screening among the most difficult-to-reach women. ${ }^{5-7}$ The HPV vaccine is currently being offered for primary prevention in young women but the benefits will not be realised for many years to come.

Screening remains the best option for prevention and yet in LMIC, and Uganda specifically, cytological (Papanicolau smear) screening programmes are cost prohibitive, resource intensive and not widely available. ${ }^{8}$ These barriers to screening, in addition to barriers of misinformation, access, psychosocial burden and lack of reliable treatment options make screening uptake highly challenging. If the new technologies of hrHPV DNA testing or HPV vaccination are to have any impact, a better understanding, and renewed focus on understanding a woman's motivation for screening is essential.

A significant cervical cancer screening barrier cited by women in both the developing and developed world is embarrassment. ${ }^{9-15}$ Embarrassment in gynaecological screening is a well-known but ill-defined phenomenon. From screening for sexually transmitted infections to cervical cancer, many women cite embarrassment as the reason for not participating in screening, ${ }^{4} 6$ 7 7 9-12 14-24 yet little is known about the specific components of screening that are most embarrassing and the wider impact this has on screening uptake and adherence. Some studies discuss lack of privacy, discomfort with sexuality, fear of judgement and religious rationale as contributors to embarrassment. ${ }^{7} 91625$ Embarrassment is commonly viewed as a static psychosocial barrier with little discussion on how it can evolve and dissipate. With such strong psychosocial barriers to screening, it follows that compliance with future testing or initiating screening at all may be threatened.

\section{CONTEXT AND SETTING}

The Advances in Screening and Prevention in Reproductive Cancers (ASPIRE-http://www. aspireafrica.ca/) project was created to fill the gap in early detection and treatment of cervical cancer in Uganda. Until now, this collaboration has conducted a baseline survey to explore the acceptability of selfcollected HPV DNA testing and attitudes towards cervical cancer screening ${ }^{26}{ }^{27}$ as well as a feasibility study enrolling 200 women and taking them from HPV swab self-collection to colposcopy and treatment. ${ }^{28}$

The key results from the initial phase of the ASPIRE assessment of 300 women in a low-resource community in Uganda showed that embarrassment was cited as a significant barrier to self-collection. ${ }^{26}$ Of those unwilling to collect a swab, $36 \%$ reported that they would be embarrassed to collect a swab at home. In contrast, of those willing to collect a swab, $2 \%$ reported that they would be embarrassed to do so. Embarrassment to collect the swab at home was a significant negative predictor for participation (adjusted OR $0.09,95 \%$ CI 0.03 to 0.29 ). ${ }^{26}$

The objectives of this study were to define embarrassment in Uganda and develop an understanding of the role of embarrassment in relation to cervical cancer screening and self-collected HPV DNA testing. In addition, the aim was to determine viable solutions to overcoming barriers to embarrassment specifically and to cervical cancer screening overall. This study was designed to better understand embarrassment as a barrier to screening with the hope of informing the development of a prospective study investigating community-based HPV self-collection.

\section{METHODS}

We conducted key stakeholder interviews with the Ugandan ASPIRE research team which included members of the department of obstetrics and gynecology at the local tertiary hospital, nurses from the local health unit and community health workers in the target community. This method was used to obtain an initial framework to understand embarrassment in Uganda. We subsequently conducted three community focus groups to further develop these ideas. The first two groups included eight women in each group, and the third group involved all participants who attended the first two focus groups. The community focus group discussion guide was developed using peer-reviewed research articles on key barriers and facilitators to cervical cancer screening ${ }^{9} \quad 2029-32$ and discussion points generated within the ASPIRE key stakeholder interviews (box 1). This methodology was used to incorporate local knowledge and cultural practice with current peerreviewed knowledge. All participants signed informed consent and their confidentiality was ensured.

A subset of key stakeholders participated in the focus groups to facilitate discussion. Local women were invited to participate through a purposive sampling lead by the ASPIRE community health workers. ${ }^{33}$ We recruited women between the ages of 30 and 69 years who lived or worked within the target community in Uganda. Using the rich knowledge of the ASPIRE community health

\section{Box 1 Focus group discussion guide}

Items included in the focus group topic guide

(1) Definition of embarrassment with regard to cervical cancer

(2) Implications of embarrassment on cervical cancer screening and treatment (including HPV self-collection)

(3) Overcoming embarrassment

(4) Other barriers to cervical cancer screening

(5) Perception of cervical cancer

(6) Evaluation and future directions for the ASPIRE project Items included in stakeholder consultation

(1-6) of the focus group topic guide

(7) Focus group methodology

(8) Focus group data analysis 
workers, we sought information-rich participants who would be willing to share their views. We recruited a total of 16 women to attend the focus groups. The first focus group was comprised of eight previous participants in the ASPIRE project. The second focus group was comprised of eight women naïve to the ASPIRE project. The third focus group was conducted with all 16 women to review results, disseminate the findings and seek clarification on any underdeveloped ideas. This recruitment strategy was specifically chosen to capture diverse perspectives from an experienced group and a naïve group. We hypothesised that the ASPIRE-experienced group would describe less embarrassment than the ASPIRE-naive group. The community health workers involved in the project acted as focus group facilitators and the ASPIRE project coordinator (Doreen Birungi) assisted in the translation and cultural interpretation of the results. Transcription and thematic analysis were undertaken following each focus group, with the goal of generating new ideas for discussion in subsequent groups. The topics were flexible and driven by the focus-group participants, in keeping with the foundation of qualitative research. ${ }^{34}$

\section{Data collection and analysis}

All stakeholder interviews and focus group discussions were audiotaped and transcribed by the primary researcher (FFT) and Luganda translator (Doreen Birungi). Workshops were undertaken in Luganda and English. The English portion of the audiotape was transcribed. The Luganda translator reviewed the audiotape and written transcript to verify appropriate translation and content. During the second review, the translator also assisted as a cultural liaison to ensure that the data correctly reflected the Ugandan cultural context. A thematic analysis of transcripts was undertaken after each focus group and themes were refined with each analysis. The stakeholder interviews were analysed and reported in the Results section and were also used to inform the content of the discussion guide used for subsequent focus groups.

A final thematic analysis was undertaken at the conclusion of the three workshops by FFT and the data were presented to the participants at a final meeting to ensure that the content was correct and reflective of the intentions of the group. ${ }^{35}$ The coding structure was developed using grounded theory and content analysis. ${ }^{36} \mathrm{~A}$ second independent thematic analysis was undertaken by MS to enhance inter-rater reliability ${ }^{37}$ and to ensure that all themes were internally convergent and externally divergent, meaning that categories were structured so that they were internally consistent but distinct from one another. ${ }^{38}$ Following the development of the code structure, a framework analysis was undertaken using the Health Belief Model. ${ }^{39}$ This framework has been utilised in understanding screening behaviours, preventative actions and illness behaviour and also been well validated in these settings. ${ }^{20} 2139$

\section{RESULTS}

\section{Demographics}

Of the 16 women that we surveyed, the average age was 44 years with a range between 30 and 57 years. The majority of women were married $(50 \%)$ and had attended primary school with or without some secondary education $(75 \%)$. Eighty-eight per cent worked outside the home and lived in the target district in Kampala within $30 \mathrm{~min}$ from the health centre (table 1).

\section{Perceived susceptibility}

Women perceived themselves to be at low risk for HPV infection, but the HIV screening model influenced perceptions for HPV screening. They could understand the need for HPV screening from their knowledge of the HIV paradigm. For some women, there was a belief that testing was only necessary for sexually active women. Similarly, for cervical cancer, women perceived themselves to be at low

Table 1 Demographic characteristics of focus group participants $(n=16)$

\begin{tabular}{|c|c|}
\hline Characteristic & $\begin{array}{l}\text { Number of } \\
\text { participants }\end{array}$ \\
\hline \multicolumn{2}{|l|}{ Age groups } \\
\hline $26-30$ & 2 \\
\hline $31-35$ & 4 \\
\hline $36-40$ & 1 \\
\hline $41-45$ & 1 \\
\hline $46-50$ & 0 \\
\hline $51-55$ & 5 \\
\hline $56-60$ & 3 \\
\hline \multicolumn{2}{|l|}{ Marital status } \\
\hline Single & 7 \\
\hline Married & 8 \\
\hline Widowed & 1 \\
\hline \multicolumn{2}{|l|}{ Education of the participant } \\
\hline No schooling or some primary schooling & 1 \\
\hline $\begin{array}{l}\text { Primary with or without some secondary } \\
\text { schooling }\end{array}$ & 12 \\
\hline Secondary & 1 \\
\hline Postsecondary & 2 \\
\hline \multicolumn{2}{|l|}{ Work outside of home } \\
\hline No & 2 \\
\hline Yes & 14 \\
\hline \multicolumn{2}{|l|}{ Live in Kisenyi } \\
\hline No & 2 \\
\hline Yes & 14 \\
\hline \multicolumn{2}{|l|}{ Housing } \\
\hline Rent & 10 \\
\hline Own & 6 \\
\hline \multicolumn{2}{|l|}{ Religion } \\
\hline 7th day adventist & 1 \\
\hline Anglican/protestant & 4 \\
\hline Catholic & 5 \\
\hline Muslim & 6 \\
\hline \multicolumn{2}{|l|}{ Time to walk to nearest health centre, min } \\
\hline$<30$ & 14 \\
\hline $30-60$ & 2 \\
\hline
\end{tabular}


risk and there was a lack of knowledge regarding the relationship between HPV and cervical cancer. In addition, most people do not seek care unless there are symptoms. One woman highlighted

For Africans its hard to go to the hospital if you are not sick. You have to actually be sick in bed before you will go for treatment. (Focus Group 1-Previous ASPIRE Participant)

\section{Perceived severity}

Women acknowledged a sense of fatalism regarding cancer and felt that 'knowing their status' would be a situation too difficult to cope with. In addition, they did not want to worry about the outcome. They felt that worrying would make the disease worse. One woman described

They don't want to know their [cervical cancer screening] status because if they know their status, they don't see any solution. They will just die, there is no treatment, there is nothing to be fixed. It is like a death sentence. (Key Stakeholder Interview)

Surprisingly, some described that they would rather have HIV because there is a perception that there is an effective treatment, compared to a cancer diagnosis that has no cure.

Nowadays, people say that if someone to gets cancer, at least let her get HIV, than getting cancer, because for HIV there is treatment, but for cancer, there is no treatment. (Focus Group 2-ASPIRE Naïve Participant)

There were also some women who felt that the testing and/or biopsy would actually cause cancer. Some women perceived that before they got a biopsy/test they were healthy and after the test, they were sick, so it must have been the test that made them sick. Women were concerned about the overbearing cost of cancer treatment in LMIC. Alternatively, those women who had an awareness of HPV perceived that HPV could be treated and this diagnosis was less severe.

\section{Perceived benefits and cues to action}

The women in both focus groups universally acknowledged that embarrassment would not be a major deterrent to screening if women had appropriate knowledge and education about the need for screening and if they had a private place to perform the self-collection. All women endorsed peer-to-peer education and engaging local leaders as some of the best strategies to recruit women and, in fact, many women had already told their friends about the project and were eager to participate in the next phase of the ASPIRE project.

Through these people who have self-collected and through more training, they also help those who have never attended the training, who have never selfcollected, to make them be confident that self-collection is not painful. You do it yourself, it's not the doctor doing it. I think that through them, more people will come to do the self-collection. (Focus Group 1-ASPIRE Participant)

Nevertheless, overall, participants did not see large barriers to expanding the project, capacity building and resources. The women were very positive that further recruitment and screening would not be a barrier. The history of the ASPIRE project since 2008 and the ongoing education initiatives have already 'sensitised' women to the topic. Some women articulated their knowledge of the importance of screening and the ability to diagnose and treat the disease early. They had a variety of suggestions such as media messages, seminars and workshops, counselling sessions and incentives as a means to improve uptake for screening.

\section{Barriers to cervical cancer screening}

Barriers to cervical cancer screening and HPV selfcollection could easily be divided into barriers inherent to screening in general, barriers related to the use of the HPV swab and overarching barriers related to the outcomes of the test (table 2). Our focus group participants felt that cervical cancer screening in general was predicated on trust in the researchers, adequate knowledge and an awareness of their risk of cervical cancer. One woman felt that a major barrier to screening was the worry that screening would incite, she described

What if I get my sample. What results will I get? That fear of getting the results...Am I positive? Am I negative? Really people fear to hear what [results] they will get, so they end up saying, I'd rather not test. I'd rather not collect, so that I may not know any results about what is happening to me. (Focus Group 1-ASPIRE Participant)

The women had valuable insight into the barriers associated with HPV self-collection. Many women admitted to the initial novelty of the swab and discomfort with inserting items into the vagina as barriers. Women were also concerned with the swab causing infection or injury. For one group, there was significant discussion regarding the hygiene and the cleanliness of vaginal discharge. Closely related to this was the associated embarrassment of having to give a swab of vaginal secretions (with a potential smell) to a health worker.

\section{Gender perspective}

Interestingly, barriers that were not endorsed included spousal permission and cultural beliefs, practices and norms. When questioned, women were universally in support of screening whether they had spousal permission or not. One woman alluded to the mistrust and lack of communication within marriages as a source of HPV risk and, as a result, felt strongly about the importance of screening.

You have to take care of your life. You can't say that my husband refused me to go for testing. It is not his life, its 
Table 2 Health belief model framework analysis

\begin{tabular}{|c|c|c|}
\hline \multirow{2}{*}{$\begin{array}{l}\text { Health Belief Model } \\
\text { parameter }\end{array}$} & \multicolumn{2}{|l|}{ ASPIRE respondents } \\
\hline & HPV self-collection & Cervical cancer \\
\hline \multirow[t]{4}{*}{ Perceived susceptibility } & Perceived risk is low & \\
\hline & Testing will cause the disease & \\
\hline & Screening is only necessary for sexually active women & \\
\hline & HIV education model increases risk awareness & $\begin{array}{l}\text { Limited knowledge of link between HPV } \\
\text { and cervical cancer }\end{array}$ \\
\hline \multirow[t]{4}{*}{ Perceived severity } & HPV can be treated & Cervical cancer is a death sentence \\
\hline & & Cervical cancer treatment is expensive \\
\hline & & No cure for cancer \\
\hline & & Would rather get HIV than cervical cancer \\
\hline \multirow[t]{3}{*}{ Perceived benefits } & Early detection & Some treatment may be beneficial \\
\hline & Treatment availability & \\
\hline & Protecting yourself & \\
\hline \multirow[t]{10}{*}{ Perceived barriers } & Lack of time & \\
\hline & Lack of knowledge & \\
\hline & Mistrust of researchers & \\
\hline & Embarrassment & \\
\hline & Worry about outcomes & \\
\hline & Health-seeking behaviour only prompted by symptoms & \\
\hline & Discomfort with inserting items into vagina & Fatalism \\
\hline & Concern with hygiene and/or vaginal discharge & Inability to cope with results \\
\hline & Fear of pain or injury & Stigma of having cancer \\
\hline & Novelty of test & \\
\hline \multirow[t]{5}{*}{ Cues to action } & Local leaders/community health workers & \\
\hline & Peer-to-peer education and recruitment & \\
\hline & Increasing knowledge & \\
\hline & Screening necessary without symptoms & \\
\hline & Fear of contracting cancer & \\
\hline Self-efficacy & Gender perspective-spousal permission not required & \\
\hline
\end{tabular}

mine. You have to protect your life. (Focus Group 2ASPIRE Naïve Participant)

These men, they always go for treatment. Like an example for HIV. They test and they are positive. They start the treatment without telling their wives, so he keeps on going for treatment, when the wife doesn't know anything. So everyone is concerned about his or her life. (Focus Group 2-ASPIRE Naïve Participant)

Women in Kisenyi also described cultural practices that normalised the insertion of items into the vagina. Not all women endorsed this activity, but some women reported inserting herbs to widen the birth canal during the later stages of pregnancy, which provided some women comfort with their genitalia.

I don't think it has to do with shyness, because women they actually douche, they use herbs for all sorts of things. Even when they are pregnant, they use herbs, it is in most of cultures here, particularly in central Uganda, you use herbs to enlarge your birth canal to make sure you don't get an episiotomy. (Key Stakeholder Interview)

\section{Embarrassment}

There were many overlapping themes with barriers to screening and the associated embarrassment. Through our focus groups and key stakeholder discussions, there were two meaningful definitions of embarrassment. The first definition was 'community embarrassment' ('kiswaaza' in Luganda). It was described as the discomfort that one may feel depending on how they are perceived by others. The second can be described as 'personal embarrassment' ('kikuswaaza' in Luganda) or shyness/ discomfort related to their own genitalia (box 2).

An important theme was the diminishment of embarrassment over time. In the group of women with previous involvement in the ASPIRE project, they described having embarrassment initially, but after multiple education meetings and actually performing self-collection, they did not feel embarrassed about screening. In fact, they noted that they would overcome their embarrassment if they knew they needed to for another reason. This was clearly described by this participant

After knowing that you are HPV positive, then the fear goes away because you want to know what is going on, so you are free to go to the doctor to have the pelvic examination to see what is going on ... you need to know what 


\section{Box 2 Factors associated with embarrassment}

Community embarrassment

Confusion of human papillomavirus (HPV) for HIV

Place of recruitment

Location of self-collection

Privacy

Relationship with health worker

Gender of the physician performing screening

Handling of the swab

Personal embarrassment

Age of participant

Novelty of the test

Lack of knowledge

next. See the doctor at that stage, no embarrassment.

(Focus Group 3-Participant)

The data demonstrate that embarrassment is not a static emotion. It is often quoted as an important barrier to screening, yet it is not acknowledged as potentially the most modifiable barrier, compared to other factors such as age, socioeconomic status and religion. This woman describes the modifiability of embarrassment

Embarrassment is not an issue concerning cervical cancer, because HIV is very shameful compared to cancer. Nowadays people don't feel ashamed because of HIV because they are used to it. So even with cancer, people will get used to it and there will be no more embarrassment, it's not an issue. Through more training and seminars, people will get to know more, they will come to self-collection and everything will be okay. (Focus Group 3-Participant)

\section{DISCUSSION}

In the setting of a largely preventable condition and the availability of a vaccine, it is a great tragedy that cases of cervical cancer continue to rise and that more research is not being carried out on the science of implementation. Significant research is focused on screening sensitivity, specificity, vaccine targets and efficacy, but the most important of these factors is whether people will engage in screening and vaccination. This study is uniquely focused on implementation and engagement of the local women in a low-resource community in Uganda in a novel screening programme that has the potential to make cervical cancer screening widely available in the community where people live and work.

The medical literature provides a limited discussion of the psychosocial aspects of screening and these factors play a vital role in screening uptake and ongoing engagement with the patient. One study by Mutyaba et $a l^{40}$ demonstrates that screening among medical professionals, who are charged with carrying out screening, is low. If even medical workers, who are meant to be the most informed, are reluctant to partake in screening, then much work needs to be carried out to change the paradigm.

\section{Health Belief Model}

The Health Belief Model provides an important framework on which to understand cervical cancer screening uptake and treatment. Our study fits into the overall context of the Health Belief Model with a specific focus on embarrassment. We found that women did not perceive themselves to be at great risk of cervical cancer, but they perceived the diagnosis to be quite severe and fatal. They did not see the benefit of screening if the results would only cause worry and a definitive treatment was not available. For those who had the knowledge that the disease could be caught early and treated, that was a significant cue to action to initiate screening. These findings are consistent with other studies exploring cervical cancer screening behaviour. ${ }^{8} 20212941$

\section{Embarrassment}

Although several themes emerged, many of these have been described previously, but by focusing on an analysis of embarrassment specifically, we found that the women of Kisenyi defined embarrassment in two forms: community embarrassment and personal embarrassment. The first is closely related to a definition by the psychology literature which describes embarrassment as the uncomfortable, self-conscious feeling a person has following the transgression of a social norm or rule. ${ }^{42}$ This is in relation to a real, or perceived, other person. Personal embarrassment is closely related to shame, which differs in that it is defined by a person's uncomfortable feeling with one's self. ${ }^{42}$

The majority of the research regarding embarrassment and health screening is in the colorectal screening literature. In this setting, Consedine and colleagues sought to further characterise embarrassment by focusing on the specific aspects of the colorectal screening encounter that engendered embarrassment. They were able to discern a distinct phenomenon called medical embarrassment which is specific to the medical encounter and is not indicative of trait embarrassment. ${ }^{43}$ Medical embarrassment was further subdivided by Consedine into bodily embarrassment and judgement concern. In his research, these two factors were shown to have significant impact in screening behaviour. ${ }^{25}{ }^{43}$ Women in our study were concerned with the handling of the swab and the potentially associated smell of the sample, which is closely related to bodily embarrassment. The women in our study also focused on the concern of being judged in their discomfort around perceptions of being tested for HIV, concerns for privacy and the importance of location of self-collection and study recruitment.

Another key finding from our study is the dynamic nature of embarrassment and other psychosocial barriers, and the profound role that acknowledging and addressing psychosocial barriers can have in the uptake 
of cervical cancer screening and treatment. Participants in our study noted that, through the ASPIRE education seminars, their knowledge of early detection and treatment increased and their fear and embarrassment of screening diminished. After learning about the positive benefits of screening, they opted to screen, despite initial psychosocial barriers. White and colleagues conducted 6 focus groups and 10 in-depth groups of women attending Visual Inspection with Acetic Acid (VIA) screening in a primary healthcare centre in Zambia. Women described similar worries and fears regarding death from cervical cancer and the associated reluctance of screening. ${ }^{41}$ In this study, women were exposed to the education programme in a local clinic in Zambia and their attitudes about screening changed as a result. This lends credence to our data and supports the importance of addressing psychosocial concerns. In fact, addressing psychosocial barriers may show greater benefit in a shorter amount of time than attempts to address other known barriers such as socioeconomic status, education level, access to services or cost of services.

\section{Overcoming psychosocial barriers}

The participants of our study reiterated the power of local leaders and peer-to-peer education several times. In a culture that often relies on community authorities, such as Sengas (paternal aunties) for health information, rather than physicians, the role of these community members is vital. ${ }^{8}$ Women often discussed the role of their peers in encouraging them to come for screening and the important role that peers have in "changing the social norm' regarding screening. What once seemed foreign and intimidating may become familiar and approachable following the advice of a peer. This has been demonstrated among female and male sex workers in Africa in the setting of HIV/AIDS screening and treatment and has great potential for cervical cancer screening and treatment. ${ }^{44}$

Women also described the importance of changing the social norms around screening through media campaigns, drama groups and overall increased awareness, similar to what has been carried out in the setting of HIV/AIDS. In the early stages of HIV/AIDS screening and treatment programmes, the stigma and fatalism associated with an HIV/AIDS diagnosis was similar to what many women are currently reporting for cervical cancer. As antiretrovirals became more widely available, education improved and the social norm changed around the topic, with more women being willing to test. It is hoped that the same can be achieved with cervical cancer screening.

\section{STRENGTHS AND LIMITATIONS}

This study is the first of its kind to specifically address embarrassment, in depth, as a psychosocial barrier to gynaecological screening. The assessment was uniquely timed following a pilot study on HPV DNA selfcollection in a community-setting, so women could comment on cervical cancer screening in general and HPV DNA testing in particular. The opinions elicited in this study were also unique in incorporating those who had been exposed to previous educational screening for cervical cancer and those who had not, to provide a diversity of perspectives.

This study was limited in its exploration of the multiple ethnic groups within the target community. We were able to access Luganda and Swahili speakers, but a significant Somali population exists in the community that was difficult to recruit due to language barriers. Furthermore, views of the most embarrassed women may not have been elicited given the focus group format. It may be that those women most embarrassed to discuss screening would be deterred by such a methodology. Unfortunately, an in-depth interview format also may not reach these women.

\section{CONCLUSIONS AND POLICY IMPLICATIONS}

This study demonstrates the important role of psychosocial barriers in cervical cancer screening and the factors that facilitate the modification of these barriers. The women in this study reported many of the same psychosocial barriers to screening (fear, anxiety, embarrassment, shame) as in other studies, yet they also noted that these diminished greatly with increasing knowledge and education. Participants overwhelmingly supported the role of peer-to-peer education in mitigating psychosocial barriers and facilitating screening uptake.

The results in their final form will be presented back to the local community for knowledge dissemination and the data will also play a critical role in the development and design of a larger study exploring the clinical outcomes associated with community-based HPV selfcollection versus VIA. In general, these data support the integration of psychosocial outcomes at the onset of any screening programme. In doing so, participants may experience less embarrassment and be more willing to engage in further screening and treatment activities.

\footnotetext{
Author affiliations

${ }^{1}$ Department of Obstetrics and Gynecology, University of British Columbia, Vancouver, British Columbia, Canada

${ }^{2}$ Department of Obstetrics and Gynecology, Makerere University/Mulago, National Referral Hospital, Kampala, Uganda

${ }^{3}$ British Columbia Center for Disease Control, Vancouver, British Columbia Canada

${ }^{4}$ Faculty of Health Sciences, Simon Fraser University, Vancouver, British Columbia, Canada

${ }^{5}$ British Columbia's Women's Hospital, Women's Health Research Institute, Vancouver, British Columbia, Canada
}

Acknowledgements The authors would like to thank Doreen Birungi, Veronica Najjuma, Harriet Nanyonga and Esther Namirimu who acted as project coordinators, community health workers and cultural consultants on this project. 
Contributors FFT was present at all focus groups, completed the transcription, thematic analysis of data and wrote a major portion of the manuscript. SMM contributed to the study design, analysis and structure of discussion, was present at focus groups, edited the manuscript and completed revisions. MuS contributed to the study design and secondary thematic analysis and edited the manuscript. CB contributed to the study design and guided the focus group design. JKB contributed to the study design and format of analysis and also edited the manuscript. MaS advised extensively in the initial study design. DMM advised in the initial study design and edited the manuscript. GSO advised in the initial study design, thematic analysis and contributed to the final editing of the manuscript.

Funding Women's Health Research Institute, Martha Piper Foundation, University of British Columbia's Branch of International Surgery.

\section{Competing interests None.}

Ethics approval University of British Columbia (Canada) and Makerere University (Uganda)

Provenance and peer review Not commissioned; externally peer reviewed.

Data sharing statement All authors had full access to the data of the study and accept full responsibility for the integrity of the data and the accuracy of the analysis. Thematic analysis and interview transcripts will be available from the corresponding author on request.

Open Access This is an Open Access article distributed in accordance with the Creative Commons Attribution Non Commercial (CC BY-NC 3.0) license, which permits others to distribute, remix, adapt, build upon this work noncommercially, and license their derivative works on different terms, provided the original work is properly cited and the use is non-commercial. See: http:// creativecommons.org/licenses/by-nc/3.0/

\section{REFERENCES}

1. Sankaranarayanan R, Ferlay J. Worldwide burden of gynaecological cancer: the size of the problem. Best Pract Res Clin Obstet Gynaecol 2006;20:207-25.

2. Katahoire R, Kivunibi G, Murokora D, et al. An assessment of the readiness for introduction of the HPV vaccine in Uganda. Afr $J$ Reprod Health 2008;12:159-72.

3. Ogilvie GS, Krajden M, van Niekerk DJ, et al. Primary cervical cancer screening with HPV testing compared with liquid-based cytology: results of round 1 of a randomised controlled trial-the HPV FOCAL Study. Br J Cancer 2012;107:1917-24.

4. Prevention A for CC. Improving screening coverage rates of cervical cancer prevention programs: a focus on communities. Cerv Cancer Prev Issues Depth, No. 4. Seattle; 2004

5. Ogilvie G, Krajden M, Maginley J, et al. Feasibility of self-collection of specimens for human papillomavirus testing in hard-to-reach women. CMAJ 2007;177:480-3.

6. Dzuba IG, Diaz EY, Allen B, et al. The acceptability of self-collected samples for HPV testing vs. the pap test as alternatives in Cervical Cancer Screening. J Womens Health Gend Based Med 2002;11:265-75.

7. Quincy BL, Turbow DJ, Dabinett LN. Acceptability of self-collected human papillomavirus specimens as a primary screen for cervical cancer. J Obstet Gynaecol (Lahore) 2012;32:87-91.

8. Mutyaba T, Faxelid E, Mirembe F, et al. Influences on uptake of reproductive health services in Nsangi community of Uganda and their implications for cervical cancer screening. Reprod Health 2007;4:4.

9. Armstrong $\mathrm{N}$, James $\mathrm{V}$, Dixon-Woods $\mathrm{M}$. The role of primary care professionals in women's experiences of cervical cancer screening: a qualitative study. Fam Pract 2011;29:462-6.

10. Mangoma JF, Chirenje MZ, Chimbari MJ, et al. An assessment of rural women's knowledge, constraints and perceptions on cervical cancer screening: the case of two districts in Zimbabwe. Afr J Reprod Health 2006;10:91.

11. Matejic B, Vukovic D, Pekmezovic T, et al. Determinants of preventive health behavior in relation to cervical cancer screening among the female population of Belgrade. Health Educ Res 2011;26:201-11.

12. Abdullahi A, Copping J, Kessel A, et al. Cervical screening: perceptions and barriers to uptake among Somali women in Camden. Public Health 2009;123:680-5.
13. Blomberg K, Ternestedt B, To S, et al. How do women who choose not to participate in population-based cervical cancer screening reason about their decision? Psychooncology 2008;569:561-9.

14. Orbell S. Pergamon cognition and affect after cervical screening: the role of previous test outcome and personal obligation in future uptake expectations. Science 1996;43:1237-43.

15. Taylor VM, Jackson JC, Tu S-P, et al. Cervical cancer screening among Chinese Americans. Cancer Detect Prev 2002;26:139-45.

16. Logan L, Mcllfatrick S. Exploring women's knowledge, experiences and perceptions of cervical cancer screening in an area of social deprivation. Eur J Cancer Care (Engl) 2011;20:720-7.

17. Guilfoyle S, Franco R, Gorin SS. Exploring older women's approaches to cervical cancer screening. Health Care Women Int 2007;28:930-50.

18. Cerigo $\mathrm{H}$, Macdonald ME, Franco EL, et al. Inuit women's attitudes and experiences towards cervical cancer and prevention strategies in Nunavik, Quebec. Int J Circumpolar Health 2012;71:17996.

19. Watkins MM, Gabali C, Winkleby M, et al. Barriers to cervical cancer screening in rural Mexico. Int J Gynecol Cancer 2002;12:475-9.

20. Johnson CE, Mues KE, Mayne SL, et al. Cervical cancer screening among immigrants and ethnic minorities: a systematic review using the health belief model. J Low Genit Tract Dis 2008;12:232-41.

21. Burak LJ, Meyer M. Using the health belief model to examine and predict college women's cervical cancer screening beliefs and behavior. Health Care Women Internat 1997;18:251-62.

22. Von Wagner C, Good a, Whitaker KL, et al. Psychosocial determinants of socioeconomic inequalities in cancer screening participation: a conceptual framework. Epidemiol Rev 2011;33:135-47.

23. Gatune JW, Nyamongo IK. An ethnographic study of cervical cancer among women in rural Kenya: is there a folk causal model? Int $J$ Gynecol Cancer 2005;15:1049-59.

24. Richardson D, Maple K, Perry N, et al. A pilot qualitative analysis of the psychosocial factors which drive young people to decline chlamydia testing in the UK: implications for health promotion and screening. Int J STD AIDS 2010;21:187-90.

25. Consedine NS, Ladwig I, Reddig MK, et al. The many faeces of colorectal cancer screening embarrassment: preliminary psychometric development and links to screening outcome. $\mathrm{Br} \mathrm{J}$ Health Psychol 2011;16:559-79.

26. Mitchell S, Ogilvie G, Steinberg M, et al. Assessing women's willingness to collect their own cervical samples for HPV testing as part of the ASPIRE cervical cancer screening project in Uganda. Int J Gynaecol Obstet Int 2011;114:111-15

27. Mitchell SM, Sekikubo M, Biryabarema C, et al. Factors associated with high-risk HPV positivity in a low-resource setting in sub-Saharan Africa. Am J Obstet Gynecol 2014;210:81.

28. Ogilvie GS, Mitchell S, Sekikubo M, et al. Results of a community-based cervical cancer screening pilot project using human papillomavirus self-sampling in Kampala, Uganda. Int $J$ Gynaecol Obstet 2013;122:118-23.

29. Wood K, Jewkes R, Abrahams N. Cleaning the womb: constructions of cervical screening and womb cancer among rural black women in South Africa. Soc Sci Med 1997;45:283-94.

30. Wellensiek N, Moodley M, Moodley J, et al. Knowledge of cervical cancer screening and use of cervical screening facilities among women from various socioeconomic backgrounds in Durban, Kwazulu Natal, South Africa. Int J Gynecol Cancer 2002;12:376-82.

31. Francis Sa, Nelson J, Liverpool J, et al. Examining attitudes and knowledge about HPV and cervical cancer risk among female clinic attendees in Johannesburg, South Africa. Vaccine 2010;28:8026-32.

32. Sankaranarayanan R, Budukh aM, Rajkumar R. Effective screening programmes for cervical cancer in low- and middle-income developing countries. Bull World Health Organ 2001;79:954-62.

33. Atkinson R, Flint J. Snowball sampling. Thousand Oaks, CA: SAGE, 2003:1044-5. Encycl Soc Sci Res Methods [Internet].

34. Ulin PR, Robinson ET, Tolley EE. Qualitative methods in public health: a field guide for applied research. Jossey-Bass, 2005

35. Franzosi R. Content analysis. Thousand Oaks, CA: SAGE, 2003:187-91. Encycl Soc Sci Res Methods.

36. Pope C, Ziebland S, Mays N. Analysing qualitative data. BMJ 2000;320:5-7.

37. Mays N, Pope C. Qualitative research in health care. Assessing quality in qualitative research. BMJ 2000;320:50-2.

38. Lincoln YS, Guba EG. Naturalistic inquiry. Beverly Hills: SAGE Publications, 1985.

39. Champion VL, Skinner Skinner. The Health Belief Model. In: Glanz K, Rimer BK, Viswanath K, eds. Heal Behav Heal Educ Theory Res Pract 3rd edn. San Francisco: Jossey-Bass, 2002:45-66. 
40. Mutyaba T, Mmiro FA, Weiderpass E. Knowledge, attitudes and practices on cervical cancer screening among the medical workers of Mulago Hospital, Uganda. BMC Med Educ 2006;6:13.

41. White HL, Mulambia C, Sinkala M, et al. "Worse than HIV" or "not as serious as other diseases"? Conceptualization of cervical cancer among newly screened women in Zambia. Soc Sci Med 2012;74:1486-93.

42. Edelmann RJ. Embarrassment: the state of research. Curr Psychol Rev 1981;1:125-37.
43. Consedine NS, Krivoshekova YS, Harris CR. Bodily embarrassment and judgment concern as separable factors in the measurement of medical embarrassment: psychometric development and links to treatment-seeking outcomes. Br J Health Psychol 2007;12(Pt 3): 439-62.

44. Geibel S, King'ola N, Temmerman M, et al. The impact of peer outreach on HIV knowledge and prevention behaviours of male sex workers in Mombasa, Kenya. Sex Transm Infect 2012;88:357-62. 